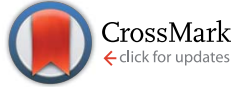

Cite this: J. Mater. Chem. A, 2015, 3, 6484

Received 20th January 2015

Accepted 15th February 2015

DOI: $10.1039 / c 5 \operatorname{ta} 00471 c$

www.rsc.org/MaterialsA

\section{Low-activated Li-ion mobility and metal to semiconductor transition in $\mathrm{CdP}_{\mathbf{2}} \mathrm{CLi}$ phases $\uparrow$}

\author{
N. Eckstein, ${ }^{a}$ I. Krüger, ${ }^{a}$ F. Bachhuber, ${ }^{\text {b }}$ R. Weihrich, ${ }^{\text {b }}$ J. E. Barquera-Lozada, ${ }^{c}$ L. van \\ Wüllen ${ }^{c}$ and Tom Nilges ${ }^{\star a}$
}

Solids with high ion mobility are of broad interest for energy storage applications. New systems featuring low-activated ion mobility are important to improve the performance in such systems. Herein we report on a model system dealing with such improved properties. $\mathrm{Li}_{0.2} \mathrm{CdP}_{2}$ was synthesized from the elements, lithium as structure stabilizer and $\mathrm{Cdl}_{2}$ as reaction promoters in sealed silica ampoules at $823 \mathrm{~K}$. It crystallizes tetragonal, in space group $144_{1} 22\left(\alpha-\mathrm{CdAs}_{2}\right.$ structure type), with lattice parameters $a=$ 7.6691(8) $\AA, c=4.4467(4) \AA$ and $V=261.53(4) \AA^{3}$. After $24 \mathrm{~h}$ of storage in air lithium ions can be removed in a spontaneous delithiation reaction resulting in $\mathrm{Li}(\mathrm{OH}) \cdot \mathrm{H}_{2} \mathrm{O}$ formation on the surface of the crystals. Formed $\alpha^{\prime}-\mathrm{CdP}_{2}$ adopts the $\alpha-\mathrm{CdAs}_{2}$ structure type. Both compounds consist of isolated cadmium atoms and helical ${ }_{\infty}^{1}\left[\mathrm{P}^{-}\right]$-chains generating empty channels suitable to accommodate $\mathrm{Li}$ ions. The heavy atom structure was determined by $\mathrm{X}$-ray diffraction methods while a full model including lithium was derived from a combined solid state NMR and quantum chemical calculation approach. An low activation barrier range in the order of 0.1 to $0.2 \mathrm{eV}$ was determined by NMR spectroscopy pointing towards an extraordinary high $\mathrm{Li}$ mobility in $\mathrm{Li}_{0.2} \mathrm{CdP}_{2}$. Of course a $\mathrm{Cd}$-based solid will have certain disadvantages like toxicity and mass for storage applications but substitution of $\mathrm{Cd}$ by suitable lighter elements can solve this issue.

\section{Introduction}

Phosphorus is an element with intriguing structure chemistry. ${ }^{1}$ In the case of $\mathrm{Cd}$ the reactivity is reasonable and binaries like $\mathrm{CdP}_{2},{ }^{2-4} \mathrm{Cd}_{3} \mathrm{P}_{2},{ }^{5,6} \mathrm{CdP}_{4},{ }^{7}$ or $\mathrm{Cd}_{7} \mathrm{P}_{10}$ (ref. 8) exist. Cd is a prominent element used in photo-semiconductors like $\mathrm{CdTe}^{9}$ or $\mathrm{Cd}_{3} P n_{2}$ (with $\left.P n=\mathrm{P}, \mathrm{As}\right)^{\mathbf{1 0 , 1 1}}$ quantum dots for solar cell applications. While solar energy conversion applications are well established features for Cd pnictides and Cd chalcogenides due to their high electron mobility, the knowledge of ion mobility in Cd pnictides is rather small. Mixed ion and electron conducting compounds are potential candidates for batteries while pure ion conductors are also important as solid state electrolytes. ${ }^{\mathbf{1 2 , 1 3}}$ Prominent solid ion conductors like garnet-type compounds

${ }^{a}$ Professur für Synthese und Charakterisierung innovativer Materialien, TU München, Lichtenbergstraße 4, 85747 Garching, Germany.E-mail: tom.nilges@lrz.tum.de; Fax: +4989289 13762; Tel: +498928913110

${ }^{b}$ Fakultät für Chemie und Pharmazie, Universität Regensburg, Universitätsstraße 31, 93040 Regensburg, Germany. E-mail: richard.weihrich@chemie.uni-r.de; Fax: +49 941943 4983; Tel: +499419434552

'Professur für Chemische Physik funktioneller Materialien am Lehrstuhl CPM, Universität Augsburg, Universitätsstr. 1, 86159 Augsburg, Germany. E-mail: leo.van. wuellen@physik.uni-augsburg.de; Fax: +49 821598 3227; Tel: +49 8215983356 $\dagger$ Electronic supplementary information (ESI) available: Cif files containing the heavy atom structures, details concerning the elemental and thermal analyses, conductivity measurements and details concerning the quantum chemical calculations. See DOI: 10.1039/c5ta00471c show conductivities of $10^{-3} \mathrm{~S} \mathrm{~cm}^{-1}$ at room temperature and activation energies of $0.3 \mathrm{eV} .^{14}$

$\mathrm{CdP}_{2}$ exists in two different modifications. At room temperature, $\alpha-\mathrm{CdP}_{2}$ crystallizes orthorhombic, in space group Pna2 (ref. $2-4$ ) while a high temperature phase $\beta-\mathrm{CdP}_{2}$ occurs above $693 \mathrm{~K}$, adopting the space group $P 4_{1} 2{ }_{1} 2 .^{3}$ The prominent structural feature in both cases is a helical ${ }_{\infty}^{1}\left[\mathrm{P}^{-}\right]$-chain coordinated to cadmium ions. A helical arsenic chain was detected in the compound $\alpha$-CdAs 2 , featuring the space group $I 4_{1} 22 .{ }^{15} \mathrm{An}$ examination of the solid solution $\mathrm{CdP}_{2}-\mathrm{CdAs}_{s}$ reveals a continuous series up to $\mathrm{CdAs}_{2-x} \mathrm{P}_{x}$ with $x=1.8$, where all representatives crystallize tetragonal, thus adopting the $\alpha-\mathrm{CdAs}_{2}$ structure type. ${ }^{16}$ It has been reported in ref. 16 that a cadmium polyphosphide in the $\alpha$-CdAs $s_{2}$ structure type could not be realized. Unfortunately, this $\alpha-\mathrm{CdAs}_{2}$ structure offers open channels ready for a coordination of mobile ions whereas such channels are not present in the known polymorphs.

Metal halides are prominent compounds to act as reaction promoters for the synthesis of kinetically stabilized materials and compounds adopting uncommon structure features. ${ }^{17}$ This feature, called mineralizer principle from now on, can also be used to selectively synthesize element allotropes of phosphorus. ${ }^{18}$ Recently, fibrous red phosphorus has been prepared by using $\mathrm{CuCl}_{2}$ (ref. 19) and orthorhombic black phosphorus can be realized by a $\mathrm{SnI}_{4} / \mathrm{Sn}$ combination. ${ }^{20-22}$ This synthesis principle was used to synthesize the present compounds. 
Herein we report on the synthesis, reactivity, quantum chemical characterization and ion mobility of $\mathrm{Li}_{0.2} \mathrm{CdP}_{2}$ and $\alpha^{\prime}$ $\mathrm{CdP}_{2}$, featuring the end member of the solid solution $\mathrm{CdAs}_{2-x} \mathrm{P}_{x}$ with $x=2.0$. The mineralizer principle has successfully been adopted using $\mathrm{CdI}_{2}$ as mineralizer agent.

\section{Experimental section}

\section{Synthesis}

$\mathrm{Li}_{0.2} \mathrm{CdP}_{2}$ was synthesized by reacting $\mathrm{Li}$ (Rockwood lithium, 99.9\%), Cd (Chempur, 99.9999\%) and red P (Chempur, $99.999+\%)$ in a molar ratio of $0.25: 0.875: 2$ in evacuated graphitized silica ampoules. $\mathrm{CdI}_{2}(25 \mathrm{mg})$, acting as mineralizer, was added to a total amount of $1 \mathrm{~g}$ starting materials. The mixture was heated up to $823 \mathrm{~K}$ within $12 \mathrm{~h}$, kept for 7 days at this temperature, and slowly cooled down to room temperature within $12 \mathrm{~h}$ afterwards. $\mathrm{Li}_{0.2} \mathrm{CdP}_{2}$ was obtained as a black powder. Impurities of cadmium or iodide were never detected the final products.

$\mathrm{Li}_{0.2} \mathrm{CdP}_{2}$ can also be prepared from the elements in ideal ratios ( $\mathrm{Li}: \mathrm{Cd}: \mathrm{P}=0.2: 1: 2$ ) without a mineralizer, resulting in a microcrystalline black powder, but only with sparse crystals. The exchange of the mineralizer from $\mathrm{CdI}_{2}$ to another mineralizer like $\mathrm{CuCl}_{2}$ resulted in completely different products. $\mathrm{Cd}_{3} \mathrm{P}_{2}$ and crystals of $\mathrm{LiP}_{15}$ have been identified after phase analysis. Impurities of copper or chlorine were neither detected in $\mathrm{Cd}_{3} \mathrm{P}_{2}$ nor in $\mathrm{LiP}_{15}$ fractions.

$\alpha^{\prime}-\mathrm{CdP}_{2}$ can be prepared from $\mathrm{Li}_{0.2} \mathrm{CdP}_{2}$ by a de-lithiation process upon exposing it to moist air. A white powder is formed on top of the needle-shaped $\mathrm{Li}_{0.2} \mathrm{CdP}_{2}$ crystals, after $24 \mathrm{~h}$ of exposure. After dissolution of the white powder in water $\mathrm{Li}_{2} \mathrm{CO}_{3}$ was found as main phase after removal of the solvent, substantiating the $\mathrm{Li}$ extraction from $\mathrm{Li}_{0.2} \mathrm{CdP}_{2}$. A full de-lithiation takes place after four weeks (Results and discussion section).

\section{EDS and ICP analyses}

Semi-quantitative EDS analysis was performed using a SEM 5900LV spectrometer (JEOL) scanning electron microscope equipped with an INCA energy dispersive microanalysis system (Oxford Instruments). An acceleration voltage of $30 \mathrm{kV}$ was used for the measurements. Another system we used was a desktop scanning microscope JCM 6000 NeoScop $^{\mathrm{TM}}$ (JEOL) equipped with an energy dispersive X-ray unit (JED 2200 JEOL). An acceleration voltage of $15 \mathrm{kV}$ was applied for the measurements. The ICP analysis were performed using an Agilent Technologies (Santa Clara, CA) model 725 Series ICP OES instrument, equipped with an Echelle optics (model Vista/7XX ES), a monochromator (model Variant Liberty) and a CCD sensor (model Vista Pro 720/725_ES, resolution < $0.01 \mathrm{~nm}$ ). Data analysis was done by the program ICP Expert II for Agilent 725 ES ICP OES.

\section{X-ray single crystal diffraction}

$\mathrm{Li}_{0.2} \mathrm{CdP}_{2}$ was stored and treated in an argon filled glovebox, while $\alpha^{\prime}-\mathrm{CdP}_{2}$ was kept in air for 7 days and subsequently washed with water to remove $\mathrm{Li}(\mathrm{OH}) \cdot \mathrm{H}_{2} \mathrm{O}$ on the surface. Single crystals of $\mathrm{Li}_{0.2} \mathrm{CdP}_{2}$ were sealed in a $0.3 \mathrm{~mm}$ glass capillary prior to the measurement. Data were collected on a Bruker APEX II diffractometer equipped with a D8 goniometer (MoK $\alpha$ radiation, $\lambda=$ $0.71069 \AA$, graphite monochromator, rotating anode source) at $123 \mathrm{~K}$. The frames were integrated with the Bruker SAINT software package ${ }^{23}$ using a narrow frame algorithm. Numerical absorption correction was done employing the SADABS routine. ${ }^{24}$ A suitable single crystal of $\alpha^{\prime}-\mathrm{CdP}_{2}$ was fixed on a glass capillary, and positioned on the goniometer head of an Oxford Xcalibur3 diffractometer (Sapphire 3 CCD detector; MoK $\alpha$ radiation, $\lambda=$ $0.71073 \AA$ A, graphite monochromator). The Oxford CrysAlis RED software was used for data processing, including an empirical absorption correction with ABSPACK. ${ }^{25}$

The space group $I 4_{1} 22$ was assigned on the basis of systematic absent reflections and the statistical analysis of the intensity distributions. The structure was solved using the superflip routine ${ }^{26}$ implemented in the Jana2006 program suite. ${ }^{27}$

\section{X-ray powder diffraction}

For the X-ray powder diffractometer analysis the sample kept under argon $\left(\mathrm{Li}_{0.2} \mathrm{CdP}_{2}\right)$ and the sample on air $\left(\alpha^{\prime}-\mathrm{CdP}_{2}\right)$ were ground and sealed in glass capillaries. Powder XRD data were collected with a STOE STADI P X-ray powder diffractometer equipped with a DECTRIS Mythen $1 \mathrm{~K}$ Detector using $\mathrm{CuK} \alpha_{1}$ radiation $(\lambda=1.54051 \AA$, curved Ge (111) monochromator). An external calibration was performed with $\mathrm{Si}(a=5.43088 \AA)$. Data were collected from $10.03^{\circ}$ to $119.755^{\circ} 2 \theta$. The XRD pattern was fitted using the Rietveld routine implemented in the program Jana2006. ${ }^{27}$

\section{Electronic structure calculations}

The first-principles calculations were carried out within the framework of DFT with exchange-correlation functionals in the generalized gradient approximation (GGA) ${ }^{28,29}$ according to Perdew-Burke-Enzerhof $(\mathrm{PBE})^{\mathbf{3 0}}$ and in the local density approximation according to Perdew and Zunger (LDA). ${ }^{31}$ Full geometry optimizations were executed with the Vienna $A b$ initio Simulation Package (VASP). ${ }^{32,33}$ All atomic site parameters and cell constants were allowed to fully relax with the conjugant gradient algorithm. The interactions between the ions and the electrons are described by the projector-augmented-wave (PAW) method $^{34}$ with a cut-off energy of $500 \mathrm{eV}$. All calculations were performed in several subsequent steps with increasing $k$-grid meshes (depending on the size of the unit cell) between $2 \times 2 \times$ 2 and $12 \times 12 \times 12$ to reach sufficient accuracy. A structure optimization was considered to be converged with a difference in total energy of less than $1 \times 10^{-6} \mathrm{eV}$ and a maximum Hellmann-Feynman force of $1 \times 10^{-4} \mathrm{eV}^{-1}$. The final values of the total energies of the investigated systems were obtained with energy differences (between last and second to last step) of less than $1 \times 10^{-3} \mathrm{eV}$ per formula unit.

\section{Solid state NMR}

Experiments were performed on a Bruker Advance III spectrometer operating at $7 \mathrm{~T}$ with resonance frequencies of 
116.6 MHz, 121.5 MHz and 300.13 MHz for ${ }^{7} \mathrm{Li},{ }^{31} \mathrm{P}$ and ${ }^{1} \mathrm{H}$, respectively. A Bruker $4 \mathrm{~mm}$ WVT MAS probe was used for the experiments. The $\mathrm{Li}_{0.2} \mathrm{CdP}_{2}$ sample was handled in a glovebox and dry $\mathrm{N}_{2}$ was employed for spinning and cooling the sample. Static ${ }^{7} \mathrm{Li}$ NMR spectra were recorded in the temperature range $117 \mathrm{~K}<T<561 \mathrm{~K}$ employing single pulse excitation and the solid echo pulse sequence for data acquisition. For the ${ }^{7} \mathrm{Li} T_{1^{-}}$ NMR measurements, the inversion recovery sequence was used. The temperature was calibrated employing the chemical shift of $\mathrm{Pb}\left(\mathrm{NO}_{3}\right)_{2}$ as a chemical shift thermometer. ${ }^{35,36}{ }^{31} \mathrm{P}$ MAS NMR and ${ }^{7}$ Li MAS NMR spectra were recorded employing spinning speeds of 8-12 kHz using the Bruker system. Additional spectra at higher spinning speeds (up to $35000 \mathrm{~Hz}$ ) for ${ }^{1} \mathrm{H}$ and ${ }^{31} \mathrm{P}$ were acquired on a Varian DMR2 NMR spectrometer operating at 11, 7 T using a Varian T3 MAS $1.6 \mathrm{~mm}$ NMR probe. Spectra are referenced as usual employing TMS for ${ }^{1} \mathrm{H}, 1 \mathrm{M} \mathrm{LiCl}$ for ${ }^{7} \mathrm{Li}$ and $85 \% \mathrm{H}_{3} \mathrm{PO}_{4}$ for ${ }^{31} \mathrm{P}$.

\section{Differential scanning calorimetry (DSC)}

Finely ground samples of phase pure $\mathrm{Li}_{0.2} \mathrm{CdP}_{2}(8.8 \mathrm{mg})$ and $\alpha^{\prime}-$ $\mathrm{CdP}_{2}(9.0 \mathrm{mg})$ were transferred to aluminum crucibles and were measured with a rate of $10 \mathrm{~K} \mathrm{~min}^{-1}$ using a Netzsch DSC $200 \mathrm{~F} 3$ Maja machine. $\mathrm{H}_{2} \mathrm{O}$, In and $\mathrm{Zn}$ were used as standards for temperature calibration. All measurements were performed under $\mathrm{N}_{2}$ atmosphere. No thermal effect was found in the temperature range from $123 \mathrm{~K}$ to $373 \mathrm{~K}$ for $\mathrm{Li}_{0.2} \mathrm{CdP}_{2} \cdot \alpha^{\prime}-\mathrm{CdP}_{2}$ cannot be transferred to $\alpha-\mathrm{CdP}_{2}$ or $\beta-\mathrm{CdP}_{2}$ up to $673 \mathrm{~K}$.

\section{DC conductivity measurements}

Total electric conductivities of $\mathrm{Li}_{0.2} \mathrm{CdP}_{2}$ and $\alpha^{\prime}-\mathrm{CdP}_{2}$ have been measured using a homemade tool, which is capable to measure pressurized powdered samples (200 $\mathrm{MPa}$, up to $2 \mathrm{~mm}$ height and $6 \mathrm{~mm}$ diameter) with a scale for measuring the height of the compressed powder. With a potentiostat (VMP-3, Biologic), a voltage of up to $10 \mathrm{~V}$ is applied to the compressed powder and the resulting current is measured. This unconventional procedure was necessary because a stable and dense pellet for impedance measurements could not be made from powdered samples in both cases. Temperature dependent conductivity measurements on single crystals are currently underway.

\section{Results and discussion}

$\mathrm{CdP}_{2}$ shows polymorphism with two known polymorphs, a low temperature $\alpha-\mathrm{CdP}_{2}$ adopting the space group $\operatorname{Pna}_{1}$ (ref. 2-4) and a high temperature $\beta$-phase stable above $693 \mathrm{~K}$, crystallizing in space group $P 4_{1} 2{ }_{1} 2 .^{3}$ A brief overview of the two $\mathrm{CdP}_{2}$ structures is given in Fig. $1 \mathrm{a}$ and $\mathrm{b}$.

The main difference is the arrangement of ${ }_{\infty}^{1}\left[\mathrm{P}^{-}\right]$-chains parallel and perpendicular towards each other featuring alternating $\mathrm{P}-\mathrm{P}$ bond lengths. $\alpha-\mathrm{CdAs}_{2}$ contains a ${ }_{\infty}^{1}\left[\mathrm{As}^{-}\right]$-chain (see Fig. 1c) with no bond length alteration and a slightly different arrangement of the Cd substructure than observed in $\alpha-\mathrm{CdP}_{2}$. Surprisingly, a $\alpha$-CdAs ${ }_{2}$-type $\mathrm{CdP}_{2}$ polymorph does not exist till now - a solid solution $\alpha-\mathrm{CdAs}_{2-x} \mathrm{P}_{x}$ has only been realized up to

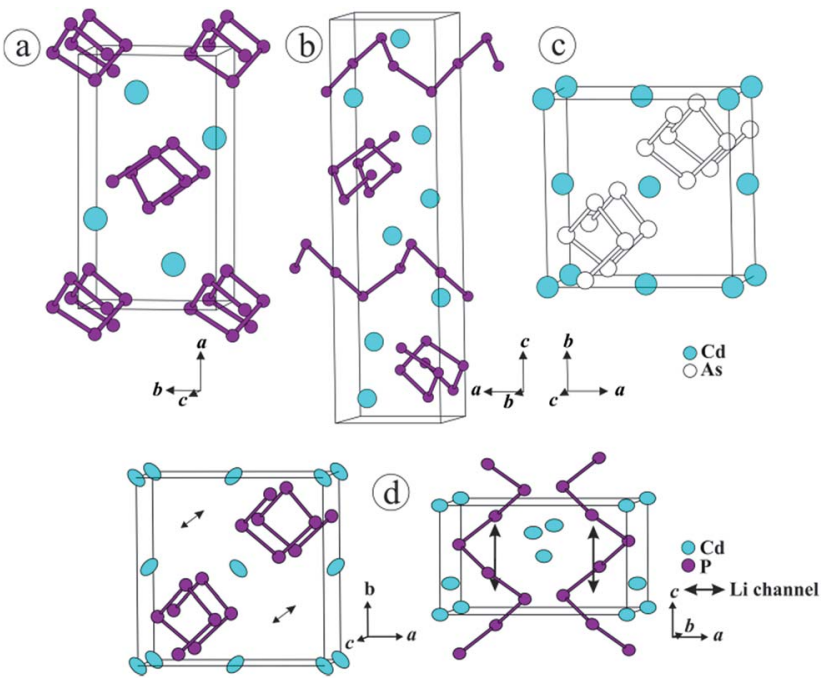

Fig. 1 Crystal structures of (a) $\alpha-\mathrm{CdP}_{2}$ in the space group $P$ na $2_{1}$ (no. 33), (b) $\beta-C d P_{2}$ in the space group $P 4_{1} 2_{1} 2$ (no. 92), (c) $\alpha-C d A s_{2}$ in the space group $14_{1} 22$ (no. 98) and (d) $\mathrm{Li}_{0.2} \mathrm{CdP}_{2}$ in space group $/ 4_{1} 22$ with displacement parameters at $90 \%$. Li could not be detected during the structure refinement and was therefore determined from quantum chemical calculations. All structures possess helical pnictide chains. Cadmium atoms are drawn as cyan, phosphorus atoms as purple, and arsenic atoms as white spheres. Li channels are marked with arrows.

$x=1.8 \cdot{ }^{16}$ We therefore started systematic investigations to close this gap to $x=0.2$ and call this new phase $\alpha^{\prime}-\mathrm{CdP}_{2}$ from now on.

All our attempts to prepare $\alpha^{\prime}-\mathrm{CdP}_{2}$, either from the elements directly or by the mineralizer principle using $\mathrm{CdI}_{2}$ or $\mathrm{CuCl}_{2}$, failed. $\mathrm{CdP}_{4}, \mathrm{Cd}_{3} \mathrm{P}_{2}$ and $\beta-\mathrm{CdP}_{2}$ were found instead. If lithium was added in small portions as starting material, $\mathrm{Li}_{0.2} \mathrm{CdP}_{2}$, adopting the $\alpha$-CdAs 2 structure type, was found.

\section{Structural characterization and elemental analysis of $\mathbf{L i}_{\text {o.2 }} \mathrm{CdP}_{2}$}

Single crystals of $\mathrm{Li}_{0.2} \mathrm{CdP}_{2}$, separated from a batch with the nominal composition $x=0.125$, have been used to perform a single crystal X-ray structure determination. An executed neutron scattering experiment of microcrystalline $\mathrm{Li}_{0.2} \mathrm{CdP}_{2}$ has also been performed, but due to the large neutron absorption cross section of $\sigma_{\mathrm{a}}=2520 \mathrm{~b}$, it was not possible to derive any structural parameters from that data.

$\mathrm{Li}_{0.2} \mathrm{CdP}_{2}$ crystallizes tetragonal, isostructural to $\alpha-\mathrm{CdAs}_{2}$, in space group $I 4_{1} 22$, with $Z=4$. The lattice parameters $(a=$ 7.6691(8) $\AA, c=4.4467(4) \AA$ and $\left.V=261.53(4) \AA^{3} ;[c / a=0.5798]\right)$ are taken from the powder analysis. Displacement parameters of $\mathrm{Cd}$ are slightly anisotropic, pointing towards a possible symmetry reduction. We found no evidences for a loss of the $4_{1}$ symmetry which would directly lead to a bond length variation within the $\mathrm{P}$ substructure. Also a loss of centering was checked but could not be confirmed. The selected symmetry was crosschecked by X-ray powder phase analysis including Rietveld refinements (see ESI $\dagger$ ).

The cadmium atoms are located on $4 a$ position $(0,0,0)$ while phosphorus occupies $8 f(0.42546(9), 0.25,0.125)$. Li could not be localized in this case. Even at $123 \mathrm{~K}$ we were not able to locate $\mathrm{Li}$ in 
the structure (see ESI $\dagger$ ). This arrangement of heavy atoms leads to four channels per unit cell along the $c$-direction, of which two of them are filled with a helical ${ }_{\infty}^{1}\left[\mathrm{P}^{-}\right]$-chain (Fig. 1d). The bond length observed within the helical ${ }_{\infty}^{1}\left[\mathrm{P}^{-}\right]$chain is $d(\mathrm{P}-\mathrm{P})=$ $2.2040(6) \AA$, lying within the expected range for covalently bonded phosphorus (2.14-2.30 $){ }^{1}{ }^{1}$ The Cd-P bond length of 2.6043(4) $\AA$ represents a well suited value reported for many cadmium polyphosphides. Examples are $\alpha-\mathrm{CdP}_{2}(d(\mathrm{Cd}-\mathrm{P})=2.495(15)$ to $2.627(15) \AA)^{4}$ or $\mathrm{Cd}_{7} \mathrm{P}_{10}(d(\mathrm{Cd}-\mathrm{P})=2.49$ to $2.85 \AA) .{ }^{8}$ The distances between neighbored cadmium atoms are close to $4 \AA$. A section of the crystal structure of $\mathrm{Li}_{0.2} \mathrm{CdP}_{2}$ is given in Fig. $1 \mathrm{~d}$.

The composition and exact Li-content was determined from single crystals by ICP-OES resulting in $\mathrm{Li}_{0.20(3)} \mathrm{Cd}_{0.90(5)} \mathrm{P}_{2.00(3)}$ (or $\mathrm{Li}: \mathrm{Cd}: \mathrm{P}=6.43: 28.93: 64.64 \mathrm{in}$ at\%). This finding is close to the expected composition but features a slightly reduced $\mathrm{Cd}$ content. An EDX analysis substantiated the 1:2 ratio of the heavy atoms. As shown later on by quantum chemical calculations, NMR spectroscopy, and phase analysis the $\mathrm{Li}_{0.2} \mathrm{Cd}_{1.0} \mathrm{P}_{2}$ composition was substantiated. In the following, we use the idealized composition $\mathrm{Li}_{0.2} \mathrm{CdP}_{2}$ for further discussions.

\section{Lithium mobility in $\mathrm{Li}_{0.2} \mathrm{CdP}_{2}$}

Due to the high Li mobility (see later on) we tried to localize $\mathrm{Li}$ by other methods than scattering techniques. We therefore decided to do quantum chemical model calculations and temperature dependent solid state NMR spectroscopy to evaluate the most probable position within the structure and to check for Li mobility in the present system.

A first hint for a high $\mathrm{Li}$ ion mobility is the reasonable reactivity of $\mathrm{Li}_{0.2} \mathrm{CdP}_{2}$ against humid air. If $\mathrm{Li}_{0.2} \mathrm{CdP}_{2}$ is stored in air for $24 \mathrm{~h}$, a white powder can be observed on the surface being identified as $\mathrm{Li}(\mathrm{OH}) \cdot \mathrm{H}_{2} \mathrm{O}$. Details are given in the ESI. $\dagger$ Assuming simple exchange reactions the formation of $\mathrm{Li}(\mathrm{OH})$. $\mathrm{H}_{2} \mathrm{O}$ is explainable.

On the crystal surface:

$$
\begin{gathered}
10 \times 0.2 \mathrm{Li}^{+}\left(\mathrm{Li}_{0.2} \mathrm{CdP}_{2}\right)+\mathrm{H}_{2} \mathrm{O}(\text { air }) \leftrightarrows 2 \mathrm{LiOH}+2 \mathrm{H}^{+} \\
\mathrm{LiOH}+\mathrm{H}_{2} \mathrm{O} \rightarrow \mathrm{Li}(\mathrm{OH}) \cdot \mathrm{H}_{2} \mathrm{O} \\
\mathrm{LiOH}+\mathrm{H}^{+} \leftrightarrows \mathrm{Li}_{2} \mathrm{O}+\mathrm{H}_{2} \mathrm{O}
\end{gathered}
$$

After dissolution and removal of water on air:

$$
2 \mathrm{Li}^{+}+2 \mathrm{OH}^{-}+\mathrm{CO}_{2} \text { (from air) } \leftrightarrows \mathrm{Li}_{2} \mathrm{CO}_{3} \downarrow+\mathrm{H}_{2} \mathrm{O}
$$

Driving force for this de-lithiation reaction is the formation of a lithium compounds on the surface of the crystals. A possible proton exchange has been addressed by NMR spectroscopy. The proton content was determined as $\mathrm{H}_{0.050(5)} \mathrm{CdP}_{2}$ (see $\mathrm{ESI}_{\dagger} \dagger$ ).

Structural characterization and elemental analysis of $\alpha^{\prime}-\mathrm{CdP}_{2}$

Carefully washed $\alpha^{\prime}-\mathrm{CdP}_{2}$ crystals were subject of a single crystal structure determination. The $\alpha-\mathrm{CdAs}_{2}$ structure type has been confirmed (see ESI†) but slightly larger lattice parameters have been observed as for $\mathrm{Li}_{0.2} \mathrm{CdP}_{2}$. Lattice parameters of $a=$ $7.6829(2) \AA, c=4.46036(11) \AA$ and $V=263.279(12) \AA^{3}[c / a=$ 0.581 ] have been derived from the scattering data, being $0.3 \%$ larger than for the lithiated compound. The effect is not drastic but outside the $3 \sigma$ criteria for all lattice parameters. Bond length of $d(\mathrm{P}-\mathrm{P})$ of $2.2104(10) \AA(d(\mathrm{P}-\mathrm{P})=2.2040(6) \AA$ in $\left.\mathrm{Li}_{0.2} \mathrm{CdP}_{2}\right)$ and $d(\mathrm{Cd}-\mathrm{P})$ of 2.6102(3) $\mathrm{A}(d(\mathrm{Cd}-\mathrm{P})=2.6043(4) \AA ̊$ in $\mathrm{Li}_{0.2} \mathrm{CdP}_{2}$ ) resulted.

$\alpha^{\prime}-\mathrm{CdP}_{2}$ can be regarded as an electron precise compound with $\mathrm{Cd}^{2+}$ ions and two-bonded $(2 \mathrm{~b}) \mathrm{P}^{-}$, resulting in $\mathrm{Cd}^{2+}\left(\mathrm{P}^{-}\right)_{2}$ following the Zintl-Klemm ${ }^{37}$ concept. It represents the former unknown end member of a solid solution $\mathrm{CdAs}_{2-x} \mathrm{P}_{x}(0<x<$ 1.8), ${ }^{16}$ which was reported in 1989 (see Fig. 2). The differences in cell volume between $\mathrm{Li}_{0.2} \mathrm{CdP}_{2}$ and $\alpha^{\prime}-\mathrm{CdP}_{2}$ are not huge but $\alpha^{\prime}$ $\mathrm{CdP}_{2}$ fits to the Vegard line ${ }^{\mathbf{4 1}}$ while $\mathrm{Li}_{x} \mathrm{CdP}_{2}$ lies significantly below.

An ICP analysis of the carefully washed black crystals after full de-lithiation resulted in $\mathrm{Cd}_{0.89(3)} \mathrm{P}_{2.00(3)}$. Li can be extracted quantitatively from $\mathrm{Li}_{0.2} \mathrm{CdP}_{2}$ by storage on air to form $\mathrm{CdP}_{2}$. Following the notation we called the new phase $\alpha^{\prime}-\mathrm{CdP}_{2}$ to illustrate the close relationship but also significant difference to $\alpha-\mathrm{CdP}_{2}$.

\section{Quantum chemical calculations}

Band structure calculations and DOS representations were performed for $\mathrm{Li}_{0.2} \mathrm{CdP}_{2}$ and its de-lithiated form $\alpha^{\prime}-\mathrm{CdP}_{2}$. $\mathrm{Li}$ positions in $\mathrm{Li}_{0.2} \mathrm{CdP}_{2}$ were determined by a supercell approach and localized within the empty channels along the crystallographic $c$-axis. While $\alpha^{\prime}-\mathrm{CdP}_{2}$ is destabilized in relation to known $\alpha-\mathrm{CdP}_{2}$ and $\beta-\mathrm{CdP}_{2}$, a substantial stabilization is found for a $\mathrm{Li}$ incorporation into the empty channels (see Fig. 3 and ESI $\dagger$ ). Substitution of Cd by Li does not lead to a significant stabilization effect and can be ruled out.

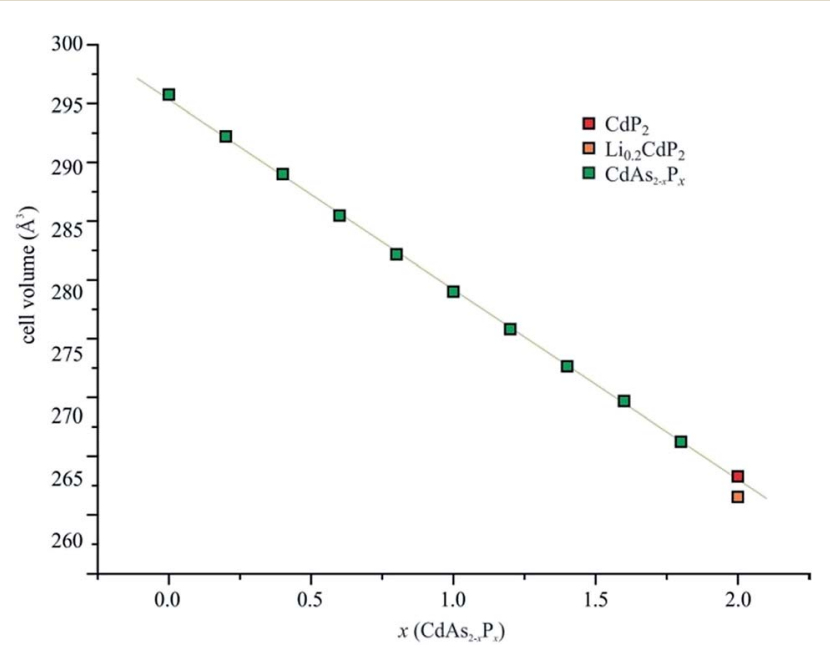

Fig. 2 Cell volumes of the solid solution $\mathrm{CdAs}_{2-x} \mathrm{P}_{x}$ derived from literature [ref. 16] for $0<x<1.8$ and from single-crystal $X$-ray experiments for $x=2$. A Vegard-like ${ }^{38}$ decrease of the cell volume is observed up to the maximum $\mathrm{P}$ content of $x=2$. 

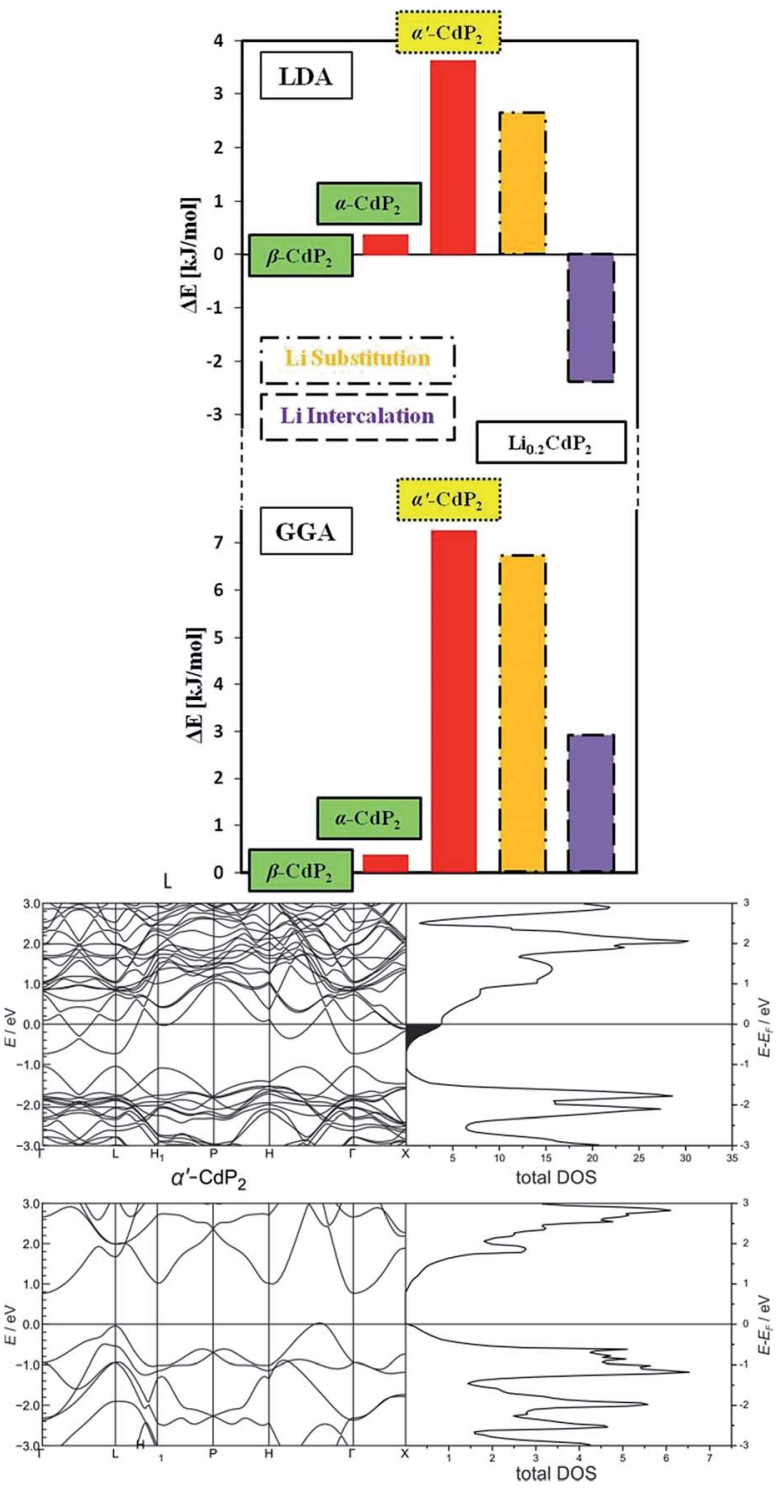

Fig. $30 \mathrm{~K}$ energies calculated by LDA and GGA for existing $\alpha$ - and $\beta$ $\mathrm{CdP}_{2}, \alpha^{\prime}-\mathrm{CdP}_{2}$ and $\mathrm{Li}_{0.2} \mathrm{CdP}_{2}$ (top). Band structure representation and total Density of States (DOS) for $\mathrm{Li}_{0.2} \mathrm{CdP}_{2}$ and $\alpha^{\prime}-\mathrm{CdP}_{2}$. The integrated DOS within the black area represents 0.2 electrons, in good accordance with the $\mathrm{Li}$ content in $\mathrm{Li}_{0.2} \mathrm{CdP}_{2}$.

$\mathrm{Li}_{0.2} \mathrm{CdP}_{2}$ is metallic featuring a pseudo band gap $0.9 \mathrm{eV}$ below the Fermi level (see Fig. 3). In contrast, $\alpha^{\prime}-\mathrm{CdP}_{2}$ is a semiconductor with a calculated band gap of $0.77 \mathrm{eV}$ (LDA) and $0.71 \mathrm{eV}$ (GGA). Total conductivity measurements of microcrystalline $\mathrm{Li}_{0.2} \mathrm{CdP}_{2}\left(10^{-5} \mathrm{~S} \mathrm{~cm}^{-1}\right)$ and $\alpha^{\prime}-\mathrm{CdP}_{2}\left(10^{-9} \mathrm{~S} \mathrm{~cm}^{-1}\right)$ exhibit a difference of four orders of magnitude at room temperature, nicely reflecting the different electronic structures. The present conductivity values from powdered samples cannot be more than a first hint due to the extreme sensitivity of the samples against mechanical stress. This feature causes disintegration of the structure upon grinding prior to the measurements. Temperature dependent conductivity measurements on single crystals are currently underway.
Obviously, the intercalation of lithium ions into the host structure leads to the closure of the band gap and the occurrence of a metal to semiconductor transition. Upon intercalation of $\mathrm{Li}$ into $\alpha^{\prime}-\mathrm{CdP}_{2}, 0.2$ electrons are located in the conduction band and the band gap vanishes. The integrated DOS (i-DOS) between the Fermi level and the pseudo gap of $\mathrm{Li}_{0.2} \mathrm{CdP}_{2}$ corresponds to 0.2 electrons, in good accordance with the expected value from the formula sum (black area in Fig. 3).

\section{Solid state NMR spectroscopy}

The ${ }^{31}$ P-MAS-NMR spectra for $\alpha^{\prime}-\mathrm{CdP}_{2}$ and $\mathrm{Li}_{0.2} \mathrm{CdP}_{2}$ are compiled in Fig. 4. In accordance with the crystal structure, we find a single phosphorous site in $\alpha^{\prime}-\mathrm{CdP}_{2}$ with an isotropic chemic shift of $\delta_{\text {iso }}=-172.6 \mathrm{ppm}$. From a simulation employing the DMFIT software ${ }^{39}$ the chemical shift anisotropy (CSA) parameters were determined as $\delta_{\mathrm{CS}}=189.5 \mathrm{ppm}$ and $\eta_{\mathrm{CS}}$ $=0.5$. We note that the spinning sidebands on the high field side of the spectrum experience some broadening, especially at higher spinning speeds.

We ascribe this to the combined action of the chemical shift anisotropy and extremely strong homo-nuclear dipolar coupling. The experimental data is found to be in good agreement with the results of quantum chemical calculations of the CSA parameters employing the WIEN2k software package, ${ }^{\mathbf{4 0}}$ which produces $\delta_{\text {iso }}=-171 \mathrm{ppm}, \delta_{\mathrm{CS}}=210 \mathrm{ppm}$ and $\eta_{\mathrm{CS}}=$ 0.46 .

For $\mathrm{Li}_{0.2} \mathrm{CdP}_{2}$, on the other hand, clearly two different $\mathrm{P}$ sites with isotropic chemical shifts of $-\mathbf{1 5 7 . 4} \mathrm{ppm}$ and $-167.4 \mathrm{ppm}$ with relative ratio of $1: 1$ can be identified. The CSA parameters for both sites are $\delta_{\mathrm{CS}}=182 \mathrm{ppm}$ and $\eta_{\mathrm{CS}}=0.6$. The virtual identical CSA parameters for $\mathrm{P}$ in $\mathrm{Li}_{0.2} \mathrm{CdP}_{2}$ and the de-lithiated $\alpha^{\prime}-\mathrm{CdP}_{2}$ sample confirm that the local ${ }^{31} \mathrm{P}$ environment in both compounds is rather similar, as suggested by the XRD results. In addition the presence of two distinct $\mathrm{P}$ sites in $\mathrm{Li}_{0.2} \mathrm{CdP}_{2}$ indirectly confirms the presence of $\mathrm{Li}$ within the structure.

The static ${ }^{7} \mathrm{Li}$ NMR spectra as a function of temperature in the temperature range $140 \mathrm{~K} \leq T \leq 295 \mathrm{~K}$, acquired employing either a single pulse excitation or a solid echo pulse sequence, are collected in Fig. 5 .

For a $I=3 / 2$ nucleus, the overall static line width represents the magnitude of the quadrupole coupling constant $C_{\mathrm{Q}}$ $=e V_{\mathrm{ZZ}} Q / h$, with $Q$ denoting the quadrupolar moment, elementary charge and $V_{\mathrm{Zz}}$ the principal component of the

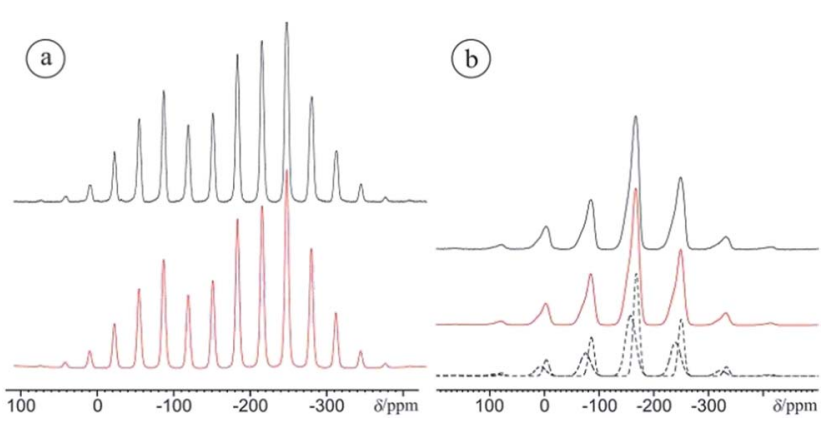

Fig. $4{ }^{31} \mathrm{P}$-MAS-NMR spectra for $\mathrm{Li}_{0.2} \mathrm{CdP}_{2}$ (a) and $\alpha^{\prime}-\mathrm{CdP}_{2}$ (b). 

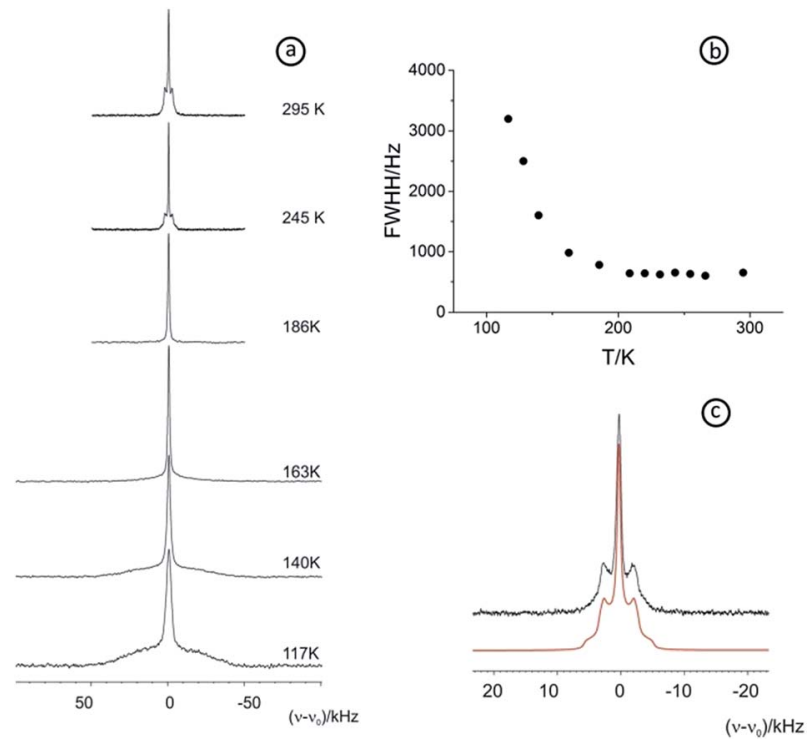

Fig. 5 (a) Static ${ }^{7}$ Li NMR spectra as a function of temperature in the temperature range $140 \mathrm{~K} \leq T \leq 295 \mathrm{~K}$ for $\mathrm{Li}_{0.2} \mathrm{CdP}_{2}$. (b) Evolution of the central signal line-width with temperature. (c) Measurement and fit for the $293 \mathrm{~K}$ signal of $\mathrm{Li}_{0.2} \mathrm{CdP}_{2}$.

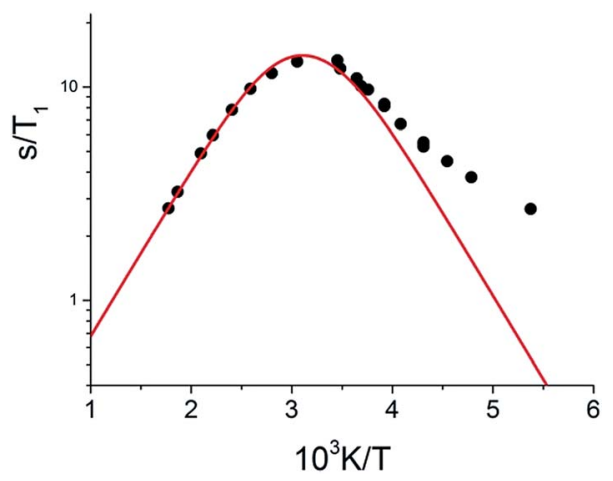

Fig. 6 Evolution of $1 / T_{1}$ plotted as a function of the inverse temperature for $\mathrm{Li}_{0.2} \mathrm{CdP}_{2}$.

electric field gradient. The narrow line in the middle of the spectrum (central transition) is only affected by the homoand hetero-nuclear dipolar interactions. Since both, the (first order) quadrupolar coupling and the dipole interaction scale with the second Legendrian $3 \cos ^{2} \beta-1$ with $\beta$ denoting the angle between the direction of the magnetic field $B_{0}$ and the principal axis of the respective interaction (quadrupolar or dipolar), the line shape will be influenced by dynamic processes, leading to an averaging of the interactions and hence a motional narrowing of the NMR line if the inverse of the corresponding correlation time exceeds the magnitude of the interaction.

In the absence of any motional process on the other hand, the line width adopts a constant line width, which is usually referred to as the rigid lattice value. From the evolution of the line shape of the static ${ }^{7} \mathrm{Li}$ NMR spectra with temperature we can clearly conclude considerable Li ion mobility in $\mathrm{Li}_{0.2} \mathrm{CdP}_{2}$. At $T<180 \mathrm{~K}$, the spectrum is characterized by a broad signal ( $m$ $= \pm 1 / 2$ to $m= \pm 3 / 2$ transitions) from which a quadrupolar coupling constant of $C_{\mathrm{Q}}=95 \mathrm{kHz}$ can be deduced. The width of the central transition at $T=140 \mathrm{~K}(4 \mathrm{kHz})$ indicates the presence of sizeable dipole coupling. Upon increasing the temperature, the overall width of the spectrum decreases to a value of $11 \mathrm{kHz}$ at ambient temperature. Thus, the quadrupolar interaction is partially averaged out due to $\mathrm{Li}$ dynamics. For an isotropic diffusive motion, a vanishing EFG and hence zero quadrupolar coupling would be expected. The presence of a residual average quadrupolar coupling as observed here indicates a hopping process in which the Li ion traces well defined positions within the crystal structure, as observed e.g. in crystalline Li ion conductors. ${ }^{41-43}$ In this situation, which is often termed anisotropic diffusion, the effective EFG, averaged over these positions, does not average to zero, but to a small residual value.

The evolution of the width of the central line with temperature is plotted in Fig. 5b. At ambient temperature, a line width of $800 \mathrm{~Hz}$ is observed. The line width does not suffer from any broadening down to temperatures of $200 \mathrm{~K}$, then a broadening sets in, resulting in a line width of $3300 \mathrm{~Hz}$ at $T=117 \mathrm{~K}$. Surprisingly, the rigid lattice regime is not reached even at these low temperatures. Employing the empirical Waugh-Fedin relation, $E_{\mathrm{A}}=0.156 \times T_{\text {onset }}$, which relates the activation energy $E_{\mathrm{A}}$ of the motional process to the onset temperature $T_{\text {onset }}$, at which the motional narrowing sets in, we can give an upper limit for the activation energy of approx. $20 \mathrm{~kJ} \mathrm{~mol}^{-1}$.

Table 1 Activation barriers of selected fast Li-ion conductors ${ }^{a}$

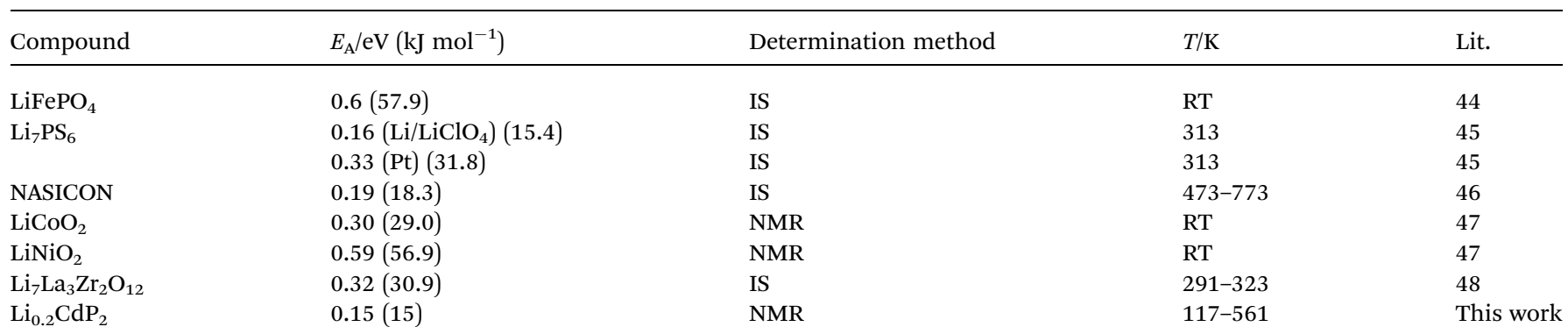

${ }^{a}$ IS: Impedance Spectroscopy NMR: Nuclear Magnetic Resonance. 
A more precise evaluation of the activation energy is possible from an analysis of the temperature dependence of the spin lattice relaxation time $T_{1}$, which was measured using a standard inversion recovery pulse sequence. The $T_{1}$ values were determined from measuring the magnetization built-up which was found to be exponential over the complete investigated temperature range. The data ( $c f$. Fig. 6) exhibits a clear $T_{1^{-}}$ minimum at approx. $310 \mathrm{~K}$. The activation energy and the correlation time of the dynamic process were then obtained from a simulation of the data employing the relaxation model of Bloembergen, Purcell and Pound (BPP), ${ }^{49}$ resulting in $E_{\mathrm{A}}=15 \mathrm{~kJ}$ $\mathrm{mol}^{-1}, \tau_{\mathrm{c}}^{0}=3.1 \times 10^{-12} \mathrm{~s}^{-1}$.

Since the low temperature side of the BPP curve is - especially in the case of disordered solids - often biased to lower values, ${ }^{50,51}$ the low temperature $T_{1}$ data was not taken into account during the simulation. We emphasize that this value is among the lowest observed activation energies for crystalline $\mathrm{Li}$ ion conductors. A selection of $\mathrm{Li}$ ion conductors is shown in Table 1. Such a low value is in line with the best known Li ion conductors. With respect to the proposed structures for $\mathrm{Li}_{0.2} \mathrm{CdP}_{2}$, the ${ }^{7} \mathrm{Li}$ NMR results clearly rule out the substitution model and favor the intercalation model.

\section{Conclusions}

Metallic $\mathrm{Li}_{0.2} \mathrm{CdP}_{2}$ was prepared by a mineralizer assisted reaction from the elements and $\mathrm{CdI}_{2}$ as reaction promoter. Semiconducting $\alpha^{\prime}-\mathrm{CdP}_{2}$ with a band gap of $\sim 0.7 \mathrm{eV}$ can be synthesized via a de-lithiation process upon a simple storage process on humid air. $\mathrm{Li}(\mathrm{OH}) \cdot \mathrm{H}_{2} \mathrm{O}$ is formed on the surface of $\mathrm{Li}_{0.2} \mathrm{CdP}_{2}$ after $24 \mathrm{~h}$ and a complete de-lithiation to $\alpha^{\prime}-\mathrm{CdP}_{2}$ takes place within weeks. A combined approach using diffraction techniques, spectroscopy and quantum chemistry was necessary to determine the crystal structures. $\mathrm{Li}_{0.2} \mathrm{CdP}_{2}$ shows a reasonable Li-ion mobility which was examined and confirmed by solid state NMR spectroscopy. An activation barrier range of $0.15 \mathrm{eV}$ has been derived from spin lattice relaxation time $\left(T_{1}\right)$ experiments, being at the low end of the activation energy spectrum known for the best solid Li-ion conducting materials. During the de-lithiation process, a metal to semiconductor transition occurs which has been examined and substantiated by quantum chemical calculations.

\section{Acknowledgements}

NE and TN thank the state of Bavaria and the DFG for the funding of an X-ray powder diffractometer.

\section{References}

1 R. Pöttgen, W. Hönle and H. G. von Schnering, Encyclopedia of Inorganic Chemistry, ed. R. B. King, Wiley, Chichester, 2nd edn, 2005, vol. VIII, pp. 4255-4308.

2 J. Goodyear and G. A. Steigmann, Acta Crystallogr., Sect. B: Struct. Crystallogr. Cryst. Chem., 1969, 25, 2371.

3 J. Berak and Z. Pruchnik, Rocz. Chem., 1968, 42, 1403-1410.
4 O. Olofsson and J. Gullman, Acta Crystallogr., Sect. B: Struct. Crystallogr. Cryst. Chem., 1970, 26, 1883-1884.

5 M. von Stackelberg and R. Paulus, Z. Phys. Chem., Abt. B, 1935, 28, 427-460.

6 K. Masumoto, S. Isomura and K. Sasaki, Phys. Status Solidi A, 1971, 6, 515-523.

7 M. von Stackelberg and R. Paulus, Z. Phys. Chem., Abt. B, 1935, 28, 427-460.

8 J. Kalicinska Karut, Z. Pruchink and K. Lukaszewicz, Rocz. Chem., 1971, 45, 1991-1992.

9 X. Wu, Sol. Energy, 2004, 6, 803-814.

10 S. Miao, S. G. Hickey, B. Rellinghaus, C. Waurisch and A. Eychmüller, J. Am. Chem. Soc., 2010, 132, 5613-5615.

11 D. K. Harris, P. M. Allen, H.-S. Han, B. J. Walker, J. Lee and M. G. Bawendi, J. Am. Chem. Soc., 2011, 133, 4676-4679.

12 J.-M. Tarascon and M. Armand, Nature, 2001, 414, 359-367. 13 A. R. West, J. Mater. Chem., 1991, 1, 157-162.

14 V. Thangadurai, S. Narayanana and D. Pinzarua, Chem. Soc. Rev., 2014, 43, 4714-4727.

15 L. Červinka and A. HrubČ, Acta Crystallogr., Sect. B: Struct. Crystallogr. Cryst. Chem., 1970, 26, 457-458.

16 V. A. Rubtsov, E. M. Smolarenko, V. M. Trukhan, V. N. Yakimovich and L. K. Orlik, Phys. Status Solidi A, 1989, 115, K155-K158.

17 S. Lange, M. Bawohl, R. Weihrich and T. Nilges, Angew. Chem., 2008, 120, 5736-5739; Angew. Chem., Int. Ed., 2008, 47, 5654-5657.

18 F. Bachhuber, J. von Appen, R. Dronskowski, P. Schmidt, T. Nilges, A. Pfitzner and R. Weihrich, Angew. Chem., 2014, 126, 11813-11817; Angew. Chem., Int. Ed., 2014, 53, 1162911633.

19 N. Eckstein, A. Hohmann, R. Weirich, T. Nilges and P. Schmidt, Z. Anorg. Allg. Chem., 2013, 639, 2741-2743.

20 S. Lange, P. Schmidt and T. Nilges, Inorg. Chem., 2007, 46, 4028-4035.

21 T. Nilges, M. Kersting and T. Pfeifer, J. Solid State Chem., 2008, 181, 1707-1711.

22 N. Eckstein, L.-A. Jantke, T. F. Fässler, J. Mink, M. Drees and T. Nilges, Eur. J. Inorg. Chem., 2014, 30, 5135-5144.

23 Bruker SAINT, 7.68 A, Bruker AXS Inc., Madison, Wisconsin, USA, 2001.

24 Bruker SADABS, 2008/2, Bruker AXS Inc., Madison, Wisconsin, USA, 2001.

25 CrysAlis RED, Version 1.171.33.34d, Oxford Diffraction Ltd., 2009.

26 L. Palatinus and G. J. Chapuis, Appl. Crystallogr., 2007, 40, 786-790.

27 V. Petřiček, M. Dušek and L. Palatinus, JANA2006 The Crystallographic Computing System, Institute of Physics, Praha, Czech Republic, 2006.

28 J. P. Perdew, K. Burke and M. Ernzerhof, Phys. Rev. Lett., 1996, 77, 3865-3868.

29 J. P. Perdew, K. Burke and M. Ernzerhof, Phys. Rev. Lett., 1997, 78, 1396.

30 J. P. Perdew and Y. Wang, Phys. Rev. B: Condens. Matter Mater. Phys., 1992, 45, 13244-13249. 
31 J. P. Perdew and A. Zunger, Phys. Rev. B: Condens. Matter Mater. Phys., 1981, 23, 5048-5079.

32 G. Kresse and J. Hafner, Phys. Rev. B: Condens. Matter Mater. Phys., 1994, 49, 14251-14269.

33 G. Kresse and J. Furthmuller, Comput. Mater. Sci., 1996, 6, 15-50.

34 G. Kresse and J. Furthmuller, Phys. Rev. B: Condens. Matter Mater. Phys., 1996, 54, 11169-11186.

35 T. Takahashi, H. Kawashima, H. Sugisawa and T. Baba, Solid State Nucl. Magn. Reson., 1999, 15, 119.

36 A. Bielecki and D. P. Burum, J. Magn. Reson., Ser. A, 1995, 116, 215.

37 E. Zintl, Angew. Chem., 1939, 52, 1.

38 L. Z. Vegard, Z. Phys., 1921, 5, 17-26.

39 D. Massiot, F. Fayon, M. Capron, I. King, S. Le Calvé, B. Alonso, J. O. Durand, B. Bujoli, Z. Gan and G. Hoatson, Magn. Reson. Chem., 2002, 40, 70-76.

40 P. Blaha, K. Schwarz, G. K. H. Madsen, D. Kvasnicka and J. Luitz, WIEN2K, An Augmented Plane Wave plus Local Orbitals Program for calculating Crystal Properties program suite, Technische Universiät, Wien, Austria, 2001.

41 L. van Wüllen, L. Hildebrandt and M. Jansen, Solid State Ionics, 2005, 176, 1449-1456.
42 L. van Wüllen, N. Sofina, L. Hildebrandt, C. Mühle and M. Jansen, Solid State Ionics, 2006, 117, 1665-1672.

43 L. van Wüllen, T. Echelmeyer, H.-W. Meyer and D. Wilmer, Phys. Chem. Chem. Phys., 2007, 9, 3298-3303.

44 C. Delacourt, L. Laffont, R. Bouchet, C. Wurm, J.-B. Leriche, M. Morcrette, J.-M. Tarascon and C. Masquelier, J. Electrochem. Soc., 2005, 152, A913-A921.

45 H.-J. Deiseroth, J. Maier, K. Weichert, V. Nickel, S.-T. Kong and C. Reiner, Z. Anorg. Allg. Chem., 2011, 637, 1287-1294.

46 G. Jasinski, P. Jasinski, B. Chachulski and A. Nowakowski, Mater. Sci., 2006, 24, 261-268.

47 K. Nakamura, H. Ohno, K. Okamura, Y. Michihiro, I. Nakabayashi and T. Kanashiro, Solid State Ionics, 2000, 135, 143-147.

48 R. Murugan, V. Thangadurai and W. Weppner, Angew. Chem., 2007, 119, 7925-7928.

49 N. Bloembergen, E. M. Purcell and R. V. Pound, Phys. Rev., 1948, 73, 679-712.

50 D. Brinkmann, Magn. Reson. Rev., 1989, 14, 101.

51 R. Winter, K. Siegmund and P. Heitjans, J. Non-Cryst. Solids, 1997, 212, 215. 